\title{
SPECULATION CONCERNING SPECIATION IN CORAL REEF FISHES
}

\author{
by
}

J.R. NURSALL ${ }^{1)}$

\begin{abstract}
The relatively constant equatorial marine environment provides a milieu within which biotic factors provide the chief selective forces acting on fish species. Increasing diversity increases evolutionary opportunity by heterotrophic magnification. Niche availability is almost limitless, space (volume) is the ultimate constraint. Abiotic thresholds, e.g., seasonal isotherms, are filter barriers to emigration to higher latitudes. Beyond such thresholds, abiotic, factors become the chief selective forces acting on fish species.

The kind of work that I do with fishes of the coral reef is that described as behavioural ecology, wherein particular species are studied in detail from a behavioural point of view. The intention being to understand the biology of that species as a unit in a community of fishes. That such communities are complex is well-acknowledged. The modish introductory statement to a paper dealing with the fishes of coral reefs has an obligatory reference to diversity and stability in reef ecosystems.

My experience lies with acanthurids and pomacentrids on the Great Barrier Reef (NURSALL 1974a, 1974b) and most particularly with blenniids in the Caribbean (NURSALL 1977). All of the species with which I have worked are permanently territorial, male and female. Pomacentrids on the Great Barrier Reef form guilds (SALE 1975), i.e., groups of species utilizing the environment in similar fashion. Consequently, in some aspects, e.g., feeding, several guild species might act almost as a single species, and indeed, will defend their territories from contiguous neighbours of a different but guild-related species as fiercely as they do against conspecifics (NURSALL 1974a, SALE 1975).

Analysis has not proceeded as far in the Caribbean, but one might except somewhat simpler guilds to be defined. In both regions, there is quite clearly vertical or stacked use made of the substratum, which in very general terms may be described as small fish (gobioid, blennioid) utilizing very small areas, larger fish (blennioid, pomacentrid) utilizing larger areas of the same substratum, still larger fish (pomacentrid,
\end{abstract}

1) Department of Zoology, University of Alberta Edmonton, Alberta T6G 2E9, Canada 


\section{J.R. NURSALL}

acanthurid) utilizing still larger areas, all these being territorial, with some home-ranging species (pomacentrid, acanthurid, scarid, serranid) being superimposed on them. Moreover mid-water species may use the same substratum for spawning purposes (pomacentrid) or for shelter (labrid, pomadasyid, holocentrid, pempherid). We see that space is not exclusive.

Some of this is niche overlap in the strictest sense. A bit more insight to this may be gained by examining food habits. I have examined the common use of algae as food by 23 species of fish that 1 know occur together on Caribbean reefs, using the food data of RANDALL (1967). These data are only partly quantitative so conclusions from them must be drawn with care.

One hundred and eight forms of algae are recorded from the guts of the 23 chosen species of fish of these algae, 62 percent are recorded from more than one species of fish, and 25 percent from more than five species. Given the problem of identification of ingested algae, the way in which the data are presented, and the large number of species not considered here $(212-23=189)$, the percentage figures presented must be conservative, i.e., more than 62 percent of the algal forms probably are used in common by reef fishes, and more than 25 percent probably are used by more than five species of fish. Table I summarizes these data as used.

The data of RANDALL (1967) may be treated in many different ways, but one conclusion emerges, whether one deals with plant or animal components of the diet: there is very little exclusive food in a reef community.

So we see that there is very little exclusive food and little exclusive space. If not exactly shared, these resources are at least partitioned.

Diversity can be recognized, by numbers and differences; stability is a more elusive concept. Whit it, I think that we are misled by our own senses to some extent. Such complications of ecological and behavioural relationship, we think, must be unchanging because of the extent of interspecific ramifications and dependencies. So many things support so many other things that the tangle cannot be unknotted. The fabric of the community is tangled like a feltwork. Or, in another metaphor, such a community resembles a complexly buffered mixture that can resist outside influences.

Perhaps we are chiefly misled by our sense of time. Our examination of the reef ecosystem temporally is very brief. Any changes in the system that are not catastrophic, are very subtle, at least to us, and take time.

The environment will govern the proximate success of any species, success being production of the next generation, the environment being all those forces that impinge on the species. 


\section{SPECULATION CONCERNING SPECIATION}

Table I. Utilization of algae by 23 selected species of lisn in the Caribbean. (Data from RANDALL 1967)

$\begin{array}{lllll}\mathrm{F} \text { i s h } & \mathrm{S} \text { p e c i e s } & \begin{array}{c}\text { Volume } \% \text { gut } \\ \text { content as algae }\end{array} & \begin{array}{c}\text { No. } \\ \text { algae }\end{array} & \begin{array}{c}\text { Classifi- } \\ \text { cation }\end{array}\end{array}$

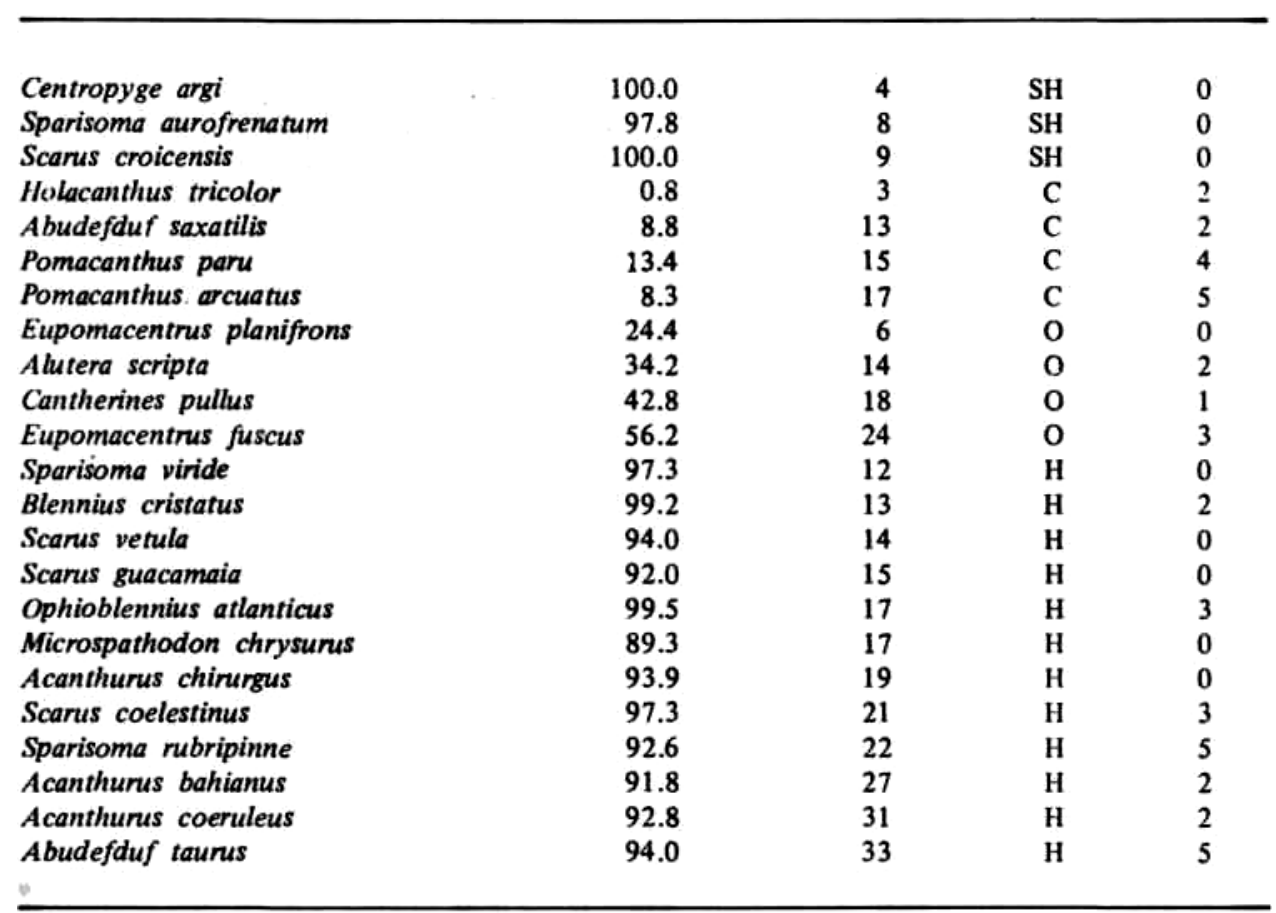

The species of fish have arbitrarily been classified here as herbivores $(\mathrm{H})$, specialized herbivores $(\mathrm{SH})$, omnivores $(\mathrm{O})$ and carnivores $(\mathrm{C})$, on the following basis :

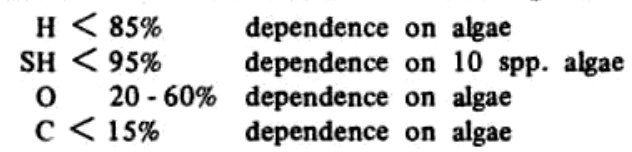

The environment has two components, biotic and abiotic. The latter are those elements of the physical environment that affect the species embedded in them, namely temperature, light and photoperiod, salinity and other chemical parameters, tidal influences, pressure, currents and other movements of the medium, and other forces, often ill-defined.

A characteristic of the tropical marine environment is that it is relatively unchanging, at least with regular periodicity. Over coral reefs photoperiod, temperature and salinity fluctuate but slightly during the 


\section{J.R. NURSALL}

course of a year. The first two in particular are latitude-controlled. Tidal forces do have their own rhythms, independent of latitude, and catastrophic events, e.g., great cyclonic storms, can take place. But random events are the sorts of events that the buffered community is protected against, i.e. a cyclone is not selective, and tidal forces, while important to many species, mostly take their effect on short term activities, e.g., daily cycle (GIBSON 1969, 1970, 1971).

What in fact is important in tropical marine waters, is the biotic part of the environment, the relationship of organism to organism. They key to this is the fact - by definition - that a heterotrophic metazoan cannot exist without the presence of another organism. The presence of any organism provides the substratum, or host, or prey, or other food for some other organisms, and they, in turn provide the environmental capacity for further development. Without doubt, starting from primordial conditions, some kind of exponential growth of diversity must have taken place in tropical waters. One sees no end to this, except ultimately by the limitation of space. Niche availability is practically limitless. The more organisms, the more niches; it might be called the principle of heterotrophic magnification. Where tropical marine systems are now on this curve of increasing diversity is not possible to define, but one guesses that although the log phase of growth of diversity may be past, we are nonetheless not yet at the stationary phase, as is sometimes implied and understood by those who marvel at the supposed stability of tropical ecosystems. In the light of space (volume) being the ultimate constraint on diversity, the study of territoriality, guilds and stacking takes on importance and added interest.

It is easy to plot the relationship between biotic and abiotic factors and latitude (Fig. 1). It might be suggested that biotic factors of the environment and diversity of species are practically the same thing. Thus a study of diversity becomes an analysis of the biotic environment.

Moreover, two contrary lines of discussion are opened up, and should be recognized. One of these is that biotic factors are the most important part of the environment, as they lead to greatest diversity. The second line of discussion is that abiotic factors are the most important, as their preeminence reduces diversity. This becomes the point of difference between studies of tropical and temperate ecology. Biotic factors are most important in tropical marine environments (and some other marine environments as SANDERS (1968, 1969) and SLOBODKIN \& SANDERS (1969) have shown. At some geographic point, to be defined for each species, physical characteristics of the environment become the chief selective agents, replacing the biological characteristics which are the selective agents, or evolutionary governors, in tropical waters. 
SPECULATION CONCERNING SPECIATION

\section{Environmental}

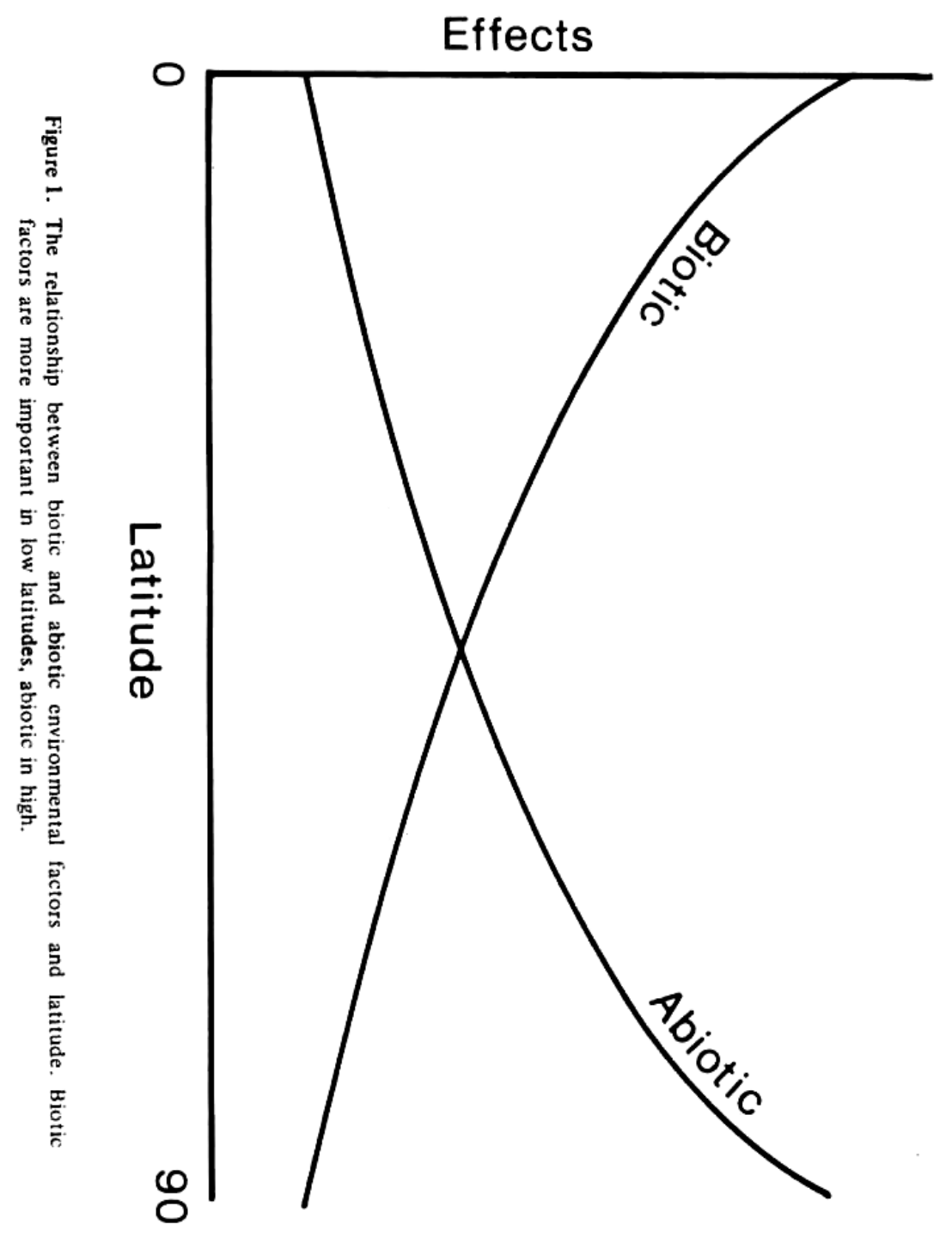




\section{J.R. NURSALL}

The replacement point will be variable and imprecise, because it will be a latitudinally controlled isopleth of some physical parameter or combination of parameters. We can think of such critical boundaries as forming barriers through which filter only those species able to survive in a physically hostile world. Probably temperature and photoperiod will be most commonly implicated. In other words, e.g., beyond some threshold temperature, only one or a few related species can extend their ranges, and this will be restricted within some absolute temperature limit. Survival, and evolutionary success, will depend upon the species in question adapting to and even taking advantage of the conditions adverse to others of its tropical biological community, e.g., a range may be extended beyond that of a predator. Further evolution, speciation, now comes to depend on success at surmounting (or utilizing) abiotic factors, rather than taking advantage of (or overcoming) biotic factors. The game is different.

Not only is the game different, but the rules are biased. It is now estimated that temperate climates have endured for only about 5 percent of the time over the last several million years, ice ages being the normal state of affairs (LIBBY 1976). That implies severe physical restriction to organisms, and a great advantage in time to the tropics for the less interrupted evolution of complex communities and diversity. The effect of this is quite evident in fish, as in other organisms.

These generally obvious conclusions are restated here to remind us of the nature of the environment in which we work, especially the marine. It is different from temperate environments, most obviously in its diversity of organisms. The concomitance of diversity and the biotic environment should provide clues to our approaches to ecological problems. There is a grand set of ecological theories, but they are largely derived from temperate zone experiences and may not be directly applicable to tropical situations, especially the coral reef ecosystem. Its particular problems can only be solved by detailed analysis of biotic interrelationships there.

\section{REFERENCES}

GIBSON, R.N. 1969. Activity rhythms in two species of Blennius from the Mediterranean. Vie et Milieu 20 : 235 - 244.

GIBSON, R.N. 1970. The tidal rhythm of activity of Coryphoblennius galerita (L.) (Teleostei, Blenniidae). Anini Behav. 18 : 539 - 543.

GIBSON, R.N. 1971. Factors affecting the rhythmic activity of Blennius pholis L. (Teleostei). Anini Behav. 19 : 336 - 343.

LIBBY, W.F. 1976. Climatology conference: letter. Science 192 : 843. 


\section{SPECULATION CONCERNING SPECIATION}

NURSALL, J.R. 1974a. Character displacement and fish behavior, especially in coral reef communities. A mer. Zool. 14 : 1090 - 1118.

NURSALL, J.R. 1974b. Some territorial behavioral attributes of the surgeonfish A canthurus lineatus at Heron Island, Queensland. Copeia 4 : 950 - 959.

NURSALL, J.R. .1977. Territoriality in redlip blennies (Ophioblennius atlanticus - Pisces: Blenniidae). J. Zool (in press).

RANDALL, J.E. 1967. Food habits of reef fishes of the West Indies. Stud. Trop. Oceanogr. Miami 5 : $665-847$.

SALE, P.F. 1975. Patterns of use of space in a guild of territorial reef fishes. Marine Biol. 29 : 89 97.

SANDERS, H.L. 1968. Marine benthic diversity! a comparative study. Amer. Natur. 102 : 243 282.

SANDERS, H.L. 1969. Benthic marine diversity and the Stability-Time Hypothesis. Brookhaven Symp. Biol. 22 : $71-81$.

SLOBODKIN, L.B. and H.L. SANDERS 1969. On the contribution of environmental predictability to species diversity. Brookhaven Symp. Biol 22 : 82 - 93. 